\title{
SIMULATION OF TEMPERATURE DISTRIBUTION AND PROPORTIONAL CONTROL EFFECTS IN HORIZONTAL FIN HEAT SINK CPU
}

\author{
T. D. Sugiarto ${ }^{1}$, R.F. Iskandar ${ }^{1}$, and I.P. Handayani ${ }^{1 *}$ \\ ${ }^{1}$ School of Electrical Engineering, Telkom University, Bandung, 40287, Indonesia
}

\begin{abstract}
This research is aimed to analyze and simulate the temperature distribution in heat sink CPU computer. The study analyzes the heat absorption from the heat source to the bottom of the heat sink, the conduction process, and the forced convection process. All processes are simulated with software Comsol Multiphysics 4.4 to obtain the optimal heat sink design. The simulation is performed by varying the number of fins, the fin thickness, the air gap between fins, the fin surface area, and the convection coefficient. The optimal design is found for heat sink with 40 pieces fins, fin thickness of $0.4 \mathrm{~mm}$, air gap of $2.4 \mathrm{~mm}$, fin surface area of $9425 \mathrm{~mm}^{2}$, and the convection coefficient of $5.26 \mathrm{~W} / \mathrm{m}^{2} . \mathrm{K}$. Further simulation shows that PID control improved the forced convection process. Proportional control (P) is reasonable enough to achieve a settled convection process. A settling temperature occurs at $241 \mathrm{~s}$ after heat is applied to the system. This is faster than the non-controlled convection process which requires $1600 \mathrm{~s}$ instead. Additional integration and derivative controls will increase stability at later time.
\end{abstract}

Keywords: heat sink, CPU, heat absorption, conduction, force convection, PID control.

\section{Introduction}

Proper temperature distribution in Central Processing Unit (CPU) computer is crucial in order to keep the system running optimally and avoid any malfunction caused by overheating. A number of analyses and simulations at different types of cooling processes such as loop heat pipe with flat evaporator [1] and mini rectangular heat fin with thermoelectric cooler [2] have previously been conducted. The results show that the geometry of heat pipe and materials used in conduction and convection processes strongly influenced the heat transfer in CPU [1-4].

In order to further improve the performance of the system, proportional-integral-derivative (PID) control is usually applied [5]. In the case of a personal computer (PC), an adaptive control has been patented [6]. This control has been claimed to improve the performance of fan and reduce cost [6].

This study attempts to simulate the temperature distribution on a horizontal fin heat sink. Simulation includes the process of heat absorption, the conductive heat transfer, and the forced convective heat transfer. We found that the temperature distribution is strongly influenced by the dimension of heat sink and the convection coefficient. Based on this simulation we determine the optimal heat sink design. Further, the proportional, integral, and derivative (PID) control is applied on the forced convection to understand the time dynamics of temperature distribution and to achieve a certain set point below an over heat temperature of $339 \mathrm{~K}$. We observed that proportional control is reasonably enough to achieve a stable convection process and a settled set point temperature is achieved $241 \mathrm{~s}$ after heat is applied to the system. Additional integration and derivative controls are observed to increase stability at a later time.

\section{Heat Sink Design and Modelling}

\subsection{Heat sink design}

The design of the horizontal heat sink used in this study is shown in Fig. 1. It consists of a copper $(\mathrm{Cu})$ block of $3 \mathrm{~mm}$ thickness which connects the heat sink into the processor, and some horizontal fins made from aluminium (Al). The area of the copper block is $16 \mathrm{~cm}^{2}$. In addition, four $\mathrm{Al}$ cylinders, each of $5 \mathrm{~mm}$ diameter are used to unite the $\mathrm{Al}$ fins. In operation, some air also flows horizontally, filling the space between the $\mathrm{Al}$ fins. The thermal conductivity $(\kappa)$, specific heat capacity $\left(\mathrm{C}_{\mathrm{p}}\right)$, and the density of the materials are given in Table 1.

Tabel 1. Material parameters

\begin{tabular}{|l|c|c|c|}
\hline Materials & $\begin{array}{c}\kappa \\
(\mathrm{W} / \mathrm{m} . \mathrm{K})\end{array}$ & $\begin{array}{c}\mathrm{C}_{\mathrm{p}} \\
(\mathrm{J} / \mathrm{kg} . \mathrm{K})\end{array}$ & $\begin{array}{c}\rho \\
\left(\mathrm{kg} / \mathrm{m}^{3}\right)\end{array}$ \\
\hline Air & 0.0261 & 1005 & 1.1855 \\
\hline $\mathrm{Al}$ & 237.38 & 900 & 2700 \\
\hline $\mathrm{Cu}$ & 401 & 395 & 8940 \\
\hline
\end{tabular}

The simulations are conducted to study the effect of fin number, the air gap between fin, fin thickness, fin area, and convection coefficient. In this 
Sugiarto et al. / Journal of Measurements, Electronics, Communications, and Systems (2015) IM0115 01

simulation, the heat distribution is assumed to be isotropic in the fin plane. The temperature of the bottom part (close to the processor) and the highest part of the heat sink are observed to monitor the heat distribution and to set the temperature below over heat temperature.

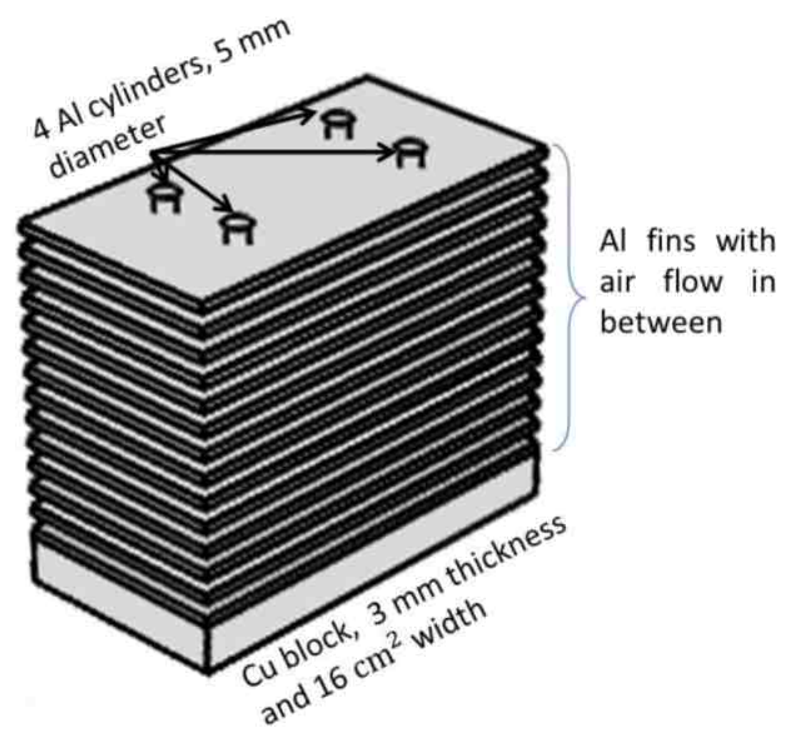

Figure 1. A schematic diagram of heat sink

\subsection{Model}

The simulation using Comsol Multiphysics 4.4 is performed based on the theoretical heat distribution in Eq. 1.

$$
\dot{Q}=m C_{p} \frac{d T}{d t}+k A_{\text {cond }} \frac{d T}{d x}+h A_{\text {conv }}\left(T-T_{\infty}\right)
$$

with $Q, m, A_{\text {cond }}, A_{\text {conv }}$, and $T_{\infty}$ are the heat flows from the processor, the mass of $\mathrm{Cu}$ block, the area of fin surface normal to the heat flow, the temperature of fin surface, and the temperature of the environment, respectively. The heat absorption, the conduction, and the convection process are presented by the first, the second, and the third terms of Eq. 1, respectively. In this simulation, the initial temperature and the environment temperature are $298 \mathrm{~K}$ while the maximum allowed temperature in the processor is 339 $\mathrm{K}$. The heat flow rate per second is equivalent to the power running on the processor $(30 \mathrm{~W})$. Initially we simulate the heat distribution without PID control and allow the system to reach any temperature below 339 $\mathrm{K}$. The PID control simulation was introduced to system in order to achieve the temperature reference by forced convection regulation. The PID control signal will adapt the temperature error to produce the convection flow rate until the convergence of the temperature distribution is achieved. In our case, the set point temperature $\left(T_{\text {set }}\right)$ is $318 \mathrm{~K}$. The simulation is performed using by applying PID control on the dynamics of convection coefficient.

$$
h(t)=K_{p}\left(T-T_{\text {set }}\right)+K_{i} \int_{0}^{t}\left(T-T_{\text {set }}\right) d t+K_{d} \frac{d}{d t}\left(T-T_{\text {set }}\right)
$$

The input parameters are proportional control $\left(K_{p}\right)$, integral control $\left(K_{i}\right)$, derivative control $\left(K_{d}\right)$, and set point temperature $\left(T_{s e t}\right)$. The initial value of $K_{p}, K_{i}$, and $K_{d}$ are determined using Ziegler-Nichols curve method. The effect of proportional control is applied in the beginning. Later, the integral and the derivative control are added. The variation of the convection coefficient $(h(t))$ is iterated until $6000 \mathrm{~s}$ and is stopped when the simulation has been convergent and $T_{\text {set }}$ of $318 \mathrm{~K}$ has been achieved.

\section{Results and Discussions}

A typical simulation result of the temperature dynamics and the temperature distribution are presented in Fig. 2. A settled temperature is achieved at $1600 \mathrm{~s}$ after heat exposure. The maximum temperature of the bottom part is $345 \mathrm{~K}$ which is 6 degree higher than the overheat temperature of $339 \mathrm{~K}$. The temperature distribution is also found to be anisotropic in the horizontal plane. A delay time of $100 \mathrm{~s}$ is observed before the temperature increasing.

Some selected simulation results are presented in Fig. 3. The maximum temperature decreases with the increasing number of fin. The overheat temperature can be avoided if the number of fin larger than 30. There is no significant effect when the number of fins larger than 50. The dimension of the air gap between fins significantly affects the conduction and convection process with the optimum air gap is around $4 \mathrm{~mm}$. The fin thickness tends to increase the maximum temperature at the bottom part while the highest part temperature tends to decrease with the increasing the fin thickness. It indicates that more heat is absorbed in thicker fin and the heat tends to be distributed in the lower part of the heat sink. As it is expected, the maximum temperature decreases for larger area of fin due to the more effective convection process. From our simulation we conclude the optimum design of heat sink consists of 40 pieces fins, fin thickness of $0.4 \mathrm{~mm}$, air gap of $2.4 \mathrm{~mm}$, and fin surface area of $9425 \mathrm{~mm}^{2}$

The variation of convection coeffient also significantly influence the temperature distribution process. Figure 4 shows the effect of the convection coefficient variation on the temperature of the bottom and the highest part of the heat sink. The maximum temperature decreases with the increasing of convection coefficient. The overheat temperature can be avoided for the convection coefficient higher than $3 \mathrm{~W} / \mathrm{m}^{2} . \mathrm{K}$. The maximum temperature does not change significantly for convection coefficient higher than $8 \mathrm{~W} / \mathrm{m}^{2} . \mathrm{K}$ 
(a)

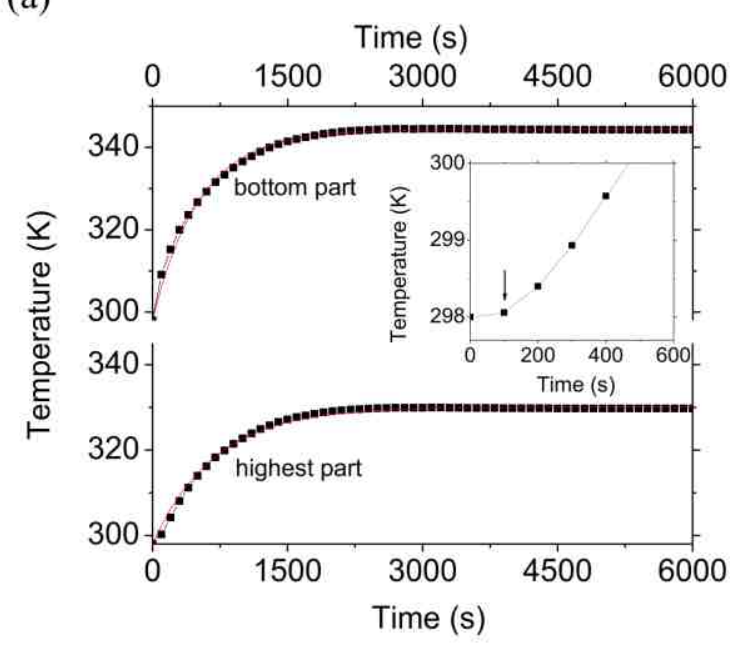

(b)

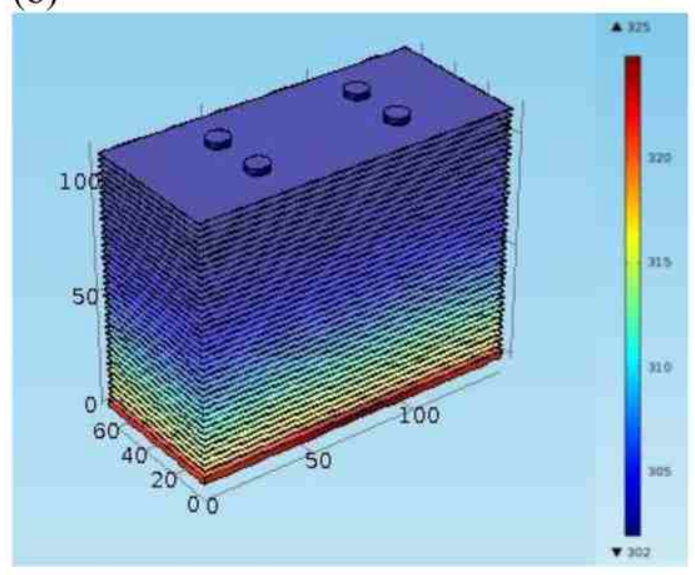

Figure 2. (a) The typical dynamics of the temperature increasing at the bottom and the highest part of the heat sink. (b) The typical temperature distribution in the entire heat sink. Inset shows the delay time before the temperature increasing.

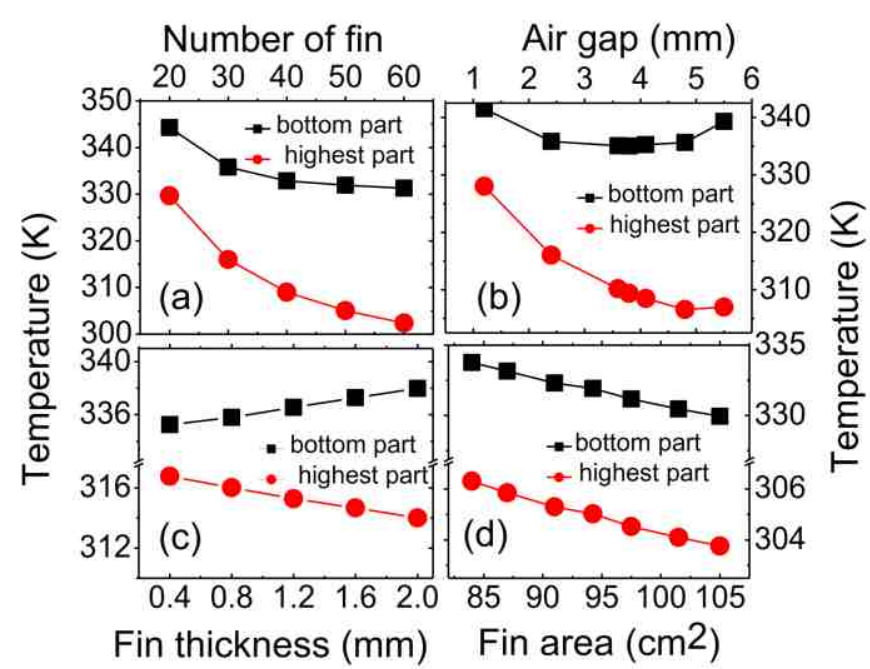

Figure 3. The effect of (a) the number of fin, (b) the air gap width, (c) the fin thickness, and (d) the fin area on the heat sink temperature at $6000 \mathrm{~s}$ after the $\mathrm{CPU}$ is switched on.

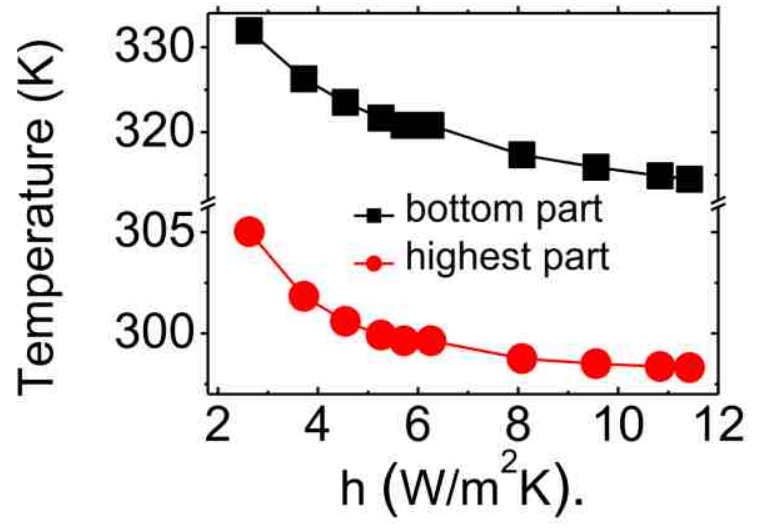

Figure 4. The effect of the convection coefficient variation on the heat sink temperature

The effects of various proportional controls are shown in Fig. 5. The convection coefficient is observed to be fluctuated for higher $K_{p}$. The inset of Fig. 5 shows that a settled temperature is reached about $241 \mathrm{~s}$ after heat exposure and is relatively dependent on $K_{p}$ value. This process is faster than the non-controlled convection process which takes about $1600 \mathrm{~s}$ to reach settled temperature.

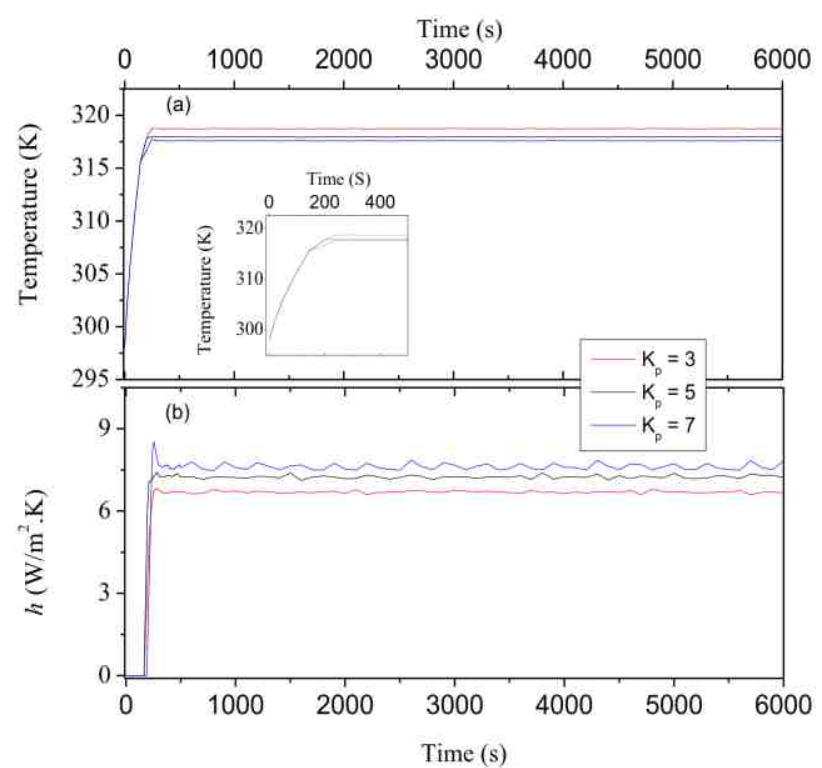

Figure 5. The dynamics of (a) the temperature and (b) the convection coefficient for various proportional control $\left(K_{\mathrm{p}}\right)$. Inset shows the temperature rising at a time less than $241 \mathrm{~s}$.

As shown in Fig. 6, a more settled temperature and convection coefficient are achieved when we added PID control. However, an overshoot in the beginning $(\approx 200$ s) should be carefully anticipated and should be kept below the overheat temperature. Considering the relation between the convection coefficient, speed of air flow, and the frequency rotation of the fan, we estimate that the fan rotation at the settled temperature is about $0.06 \mathrm{rps}$ for the case of laminar air flow and the fan diameter of $0.14 \mathrm{~m}$. 
Sugiarto et al. / Journal of Measurements, Electronics, Communications, and Systems (2015) IM0115 01
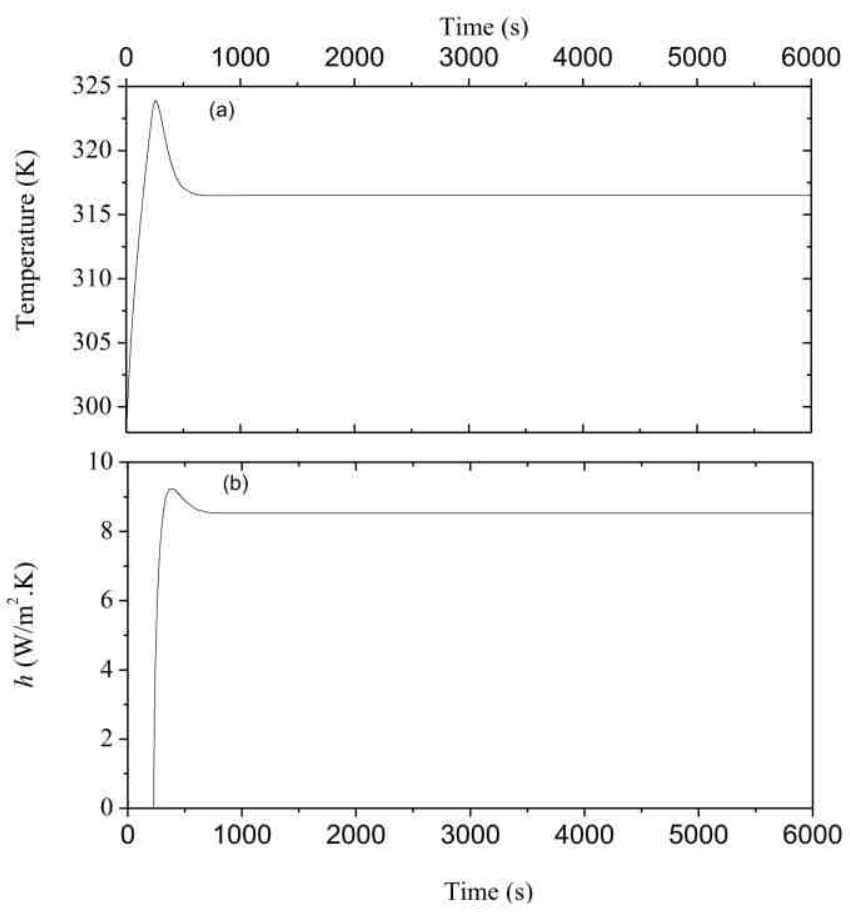

Figure 6. The dynamics of the temperature and the convection coefficient for $K_{p}=5.927, K_{i}=0.054$ and $K_{d}=164$.

\section{Conclusions}

The temperature distribution simulation has been performed using COMSOL Multiphysics. The effect of the fin number, the air gap between fin, the fin thickness, the fin area, and the convection coefficient are evaluated to obtain the optimal design of heat sink. Those parameters are found to crucially influence the maximum temperature. Introducing proportional control is observed to accelerate the settling time. The additional integration and derivative controls do not significantly influence the temperature distribution and settling time.

\section{Acknowledgement}

We acknowledge T.A. Ajiwiguna for his valuable comments and discussions.

*iphandayani@telkomuniversity.ac.id

\section{References}

[1] R. Singh, A. Akbarzadeh, C. Dixon, M. Mochizuki, and R. R. Riehl, Miniature Loop Heat Pipe With Flat Evaporator for Cooling Computer CPU, IEEE Transactions on Components and Packaging technologies 30 (2007) 42-49.

[2] P. Naphon and S. Wiriyasart, Liquid cooling in the mini-rectangular fin heat sink with and without thermoelectric for CPU, International Communications in Heat and Mass Transfer 36 (2009) 166-171
[3] Chyi-Tsong Chen, Ching-Kuo Wu, and Chyi Hwang, Optimal Design and control of CPU Heat sink Processes, IEEE Transactions on Components and Packaging Technologies 31 (1) (2008)

[4] R. Mohan, Dr. P. Govindarajan, Thermal Analysis of CPU with Composite Pin Fin Heat sinks, International Journal of Engineering Science and Technology 2 (9) (2010) 40514062

[5] Q-G Wang,Member, T-H Lee, H-W Fung, Q. $\mathrm{Bi}$, and $\mathrm{Y}$. Zhang, PID Tuning for Improved Performance, IEEE Transactions on Control Systems Technology 7 (4) (1999), 457-465.

[6] David Murray, Dennis O'Brien, Randy Goldberg, Adaptive controller for PC cooling fans, US Patent US20060108962 A1 (2006).

\section{Author information}

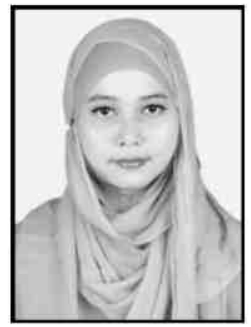

Tresna Dewi Sugiarto received her bachelor from Telkom University, Indonesia in 2015. Her project focuses on thermal analysis and simulation using COMSOL Multiphysics. She is now working in a company.

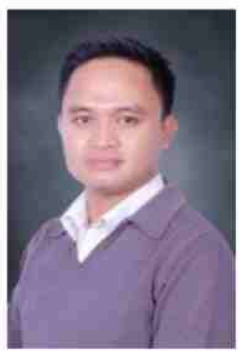

Reza Fauzi Iskandar received his master degree from Bandung Institute of Technology in 2010. His major is in adaptive control and mobile robot tracking trajectory

His current projects involve automatic control, dynamical systems, and electric power plants.

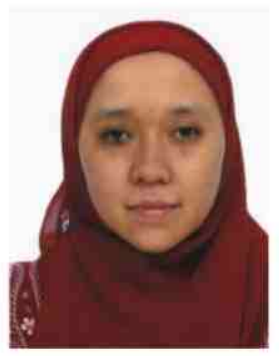

Ismudiati Puri Handayani received her doctoral degree from University of Groningen, The Netherlands, in 2014. Her major is condensed matter physics. Her current projects involve

thermal analysis as well as electrical and optical characterization. 